\title{
Randomized Observational Multicenter Study to Assess the Efficacy and Safety of the Association of Fortigel (10 Gr) and Fucoidan (100 Mg) in Patients with Gonarthrosis
}

\author{
Martin-Martin LS ${ }^{1 *}$, Pierluigi B ${ }^{2}$, La Medica C ${ }^{3}$, Melis G ${ }^{4}$, Nuvoli G5 , Piccinni V6, \\ Pietrapertosa $\mathrm{M}^{7}$, Vincenti $\mathrm{B}^{8}$, Vinicola $\mathrm{V}^{9}$ \\ ${ }^{1}$ Department of Internal Medicine, "Regina Apostolorum" Hospital, Albano Laziale (Rome-Italy) \\ ${ }^{2}$ Department of Orthopedics, "San Giovanni Calibita-Fatebenefratelli" Hospital, (Rome) \\ ${ }^{3}$ Department of Orthopedics, "Madre GiuseppinaVannini" Hospital, (Rome) \\ ${ }^{4}$ Department of Orthopedics, "Marino" Hospital, Alghero (Sassari-Italy) \\ ${ }^{5}$ Department of Rheumatology, ASL 1, Sassari \\ ${ }^{6}$ Department of Orthopedics, Rome \\ ${ }^{7}$ Department of Orthopedics, ASL Rome G (Rome) \\ ${ }^{8}$ Department of Orthopedics, ASL Rome H (Rome) \\ ${ }^{9}$ Department of Rheumatology, IRCSS "Fondazione Santa Lucia", Rome
}

Received: November 01, 2016; Accepted: November 15, 2016; Published: November 22, 2016

*Corresponding author: Martin-Martin LS, Department of Internal Medicine, "Regina Apostolorum" Hospital, Albano Laziale (Rome-Italy).

\begin{abstract}
Purpose: In order to further elucidate the efficacy and safety of some nutritional supplements on gonarthrosis, we have conducted a preliminary randomized multicenter $(n=9)$ observational study comparing the effects of an association of Fortigel $(10 \mathrm{gr})$ and Fucoidan $(100 \mathrm{mg})($ ACTEN $($ ) versus another commonly therapeutically used formulation based on Glucosamine (500mg), Chondroitin Sulfate (400mg) hyaluronic Acid (50 mg) and Vitamin C (100 mg) (COMBIART).

Patients and Methods: The protocol was administered over a 12-weeks period in a population $(\mathrm{n}=126)$ aged $40-65$ years, with diagnosed mild-tomoderate Osteoarthritis (OA) of the knee (grade 2-3 of Kellgren Lawrence grading scale).Safety was measured by closely monitoring adverse events. Efficacy was measured by grading evaluations, at basal, 1 month and 3 months controls, of the Visual Analog Scale (VAS) and the Lequesnealgo functional index for severity of osteoarthritis (LAI) for particular functionality.

Results: Both groups showed an important reduction $(\mathrm{P}<0.0001)$ in the mean visual analog scale values at $\mathrm{T} 1(28.5 \%$ ACTEN $®, 21.3 \%$ COMBIART at 1 month) and T3 (49.4\% ACTEN $囚, 40.1 \%$ COMBIART at 3 months), as well as a marked reduction in the Lequesnealgo functional index means $(\mathrm{P}<0.0001)$ (ACTEN@ 28.9\% T1 44.9\% T3, COMBIART T1 21.3\% T3 37\%). The effect seems to be time dependent, as the mean values decrease further for both parameters from T1 to T2 ( $<<0.0001$, for VAS for both groups; P 0.0011 for ACTEN $®$ group, P 0.0064 Control group for LAI). No statistically significant difference was found between the ACTEN $®$ group and the COMBIART group at time $\mathrm{T} 1$ or $\mathrm{T} 3$. These interesting preliminary data will be further investigated on a larger scale.

Conclusions: Fortigel $\circledast(10 \mathrm{gr})$ and Fucoidan $(100 \mathrm{mg})($ ACTEN $®)$ taken as oral nutritional supplements have a significant impact as therapeutic intervention for knee osteoarthritis as indicated by the marked decrease in VAS and LAI values over the course of the treatment. A similar effect, as expected, has been confirmed in the COMBIART group, and no statistically significant difference has been detected between the two groups.
\end{abstract}

\section{Introduction}

Osteoarthritis $(\mathrm{OA})$ is a very common, slowly progressive joint condition that causes significant discomfort and disability in the adult population. The prevalence of the condition increases with age, with well-known risk factors such as genetics, obesity, local trauma, and occupation. Important radiographic changes of knee $\mathrm{OA}$ are found in $1 \%$ of adults of 25-35 years of age and increase almost to $50 \%$ in elders aged 75 years and older. OA of the hips and knees are the most common complaint in the adult population.

Osteoarthritis has an inflammatory component, and a tissue breakdown component, which result in pain and stiffness [1] in these crucial weight-bearing joints. This often imposes an important disability, leading to an increased difficulty in undertaking normal activities of daily life, up to requiring joint replacement surgery in the most severe of cases.

Acetaminophen and Non Steroidal Anti-Inflammatory Drugs (NSAIDs) are common treatments for patients with osteoarthritis to cope with pain and stiffness, in severe conditions on a daily basis. For this reason, in recent years many studies have focused on alternative molecules and nutritional supplements as therapeutic options to achieve cartilage tissue repair, while bypassing the negative effects of cyclooxygenase 2 (COX-2) inhibitors and other NSAIDs. Glucosamine has been extensively studied [2-18] showing positive results in the clinical management of pain and structural improvements [19]. Chondroitin sulfate coupled to Glucosamine, or by itself, has been the center of significant studies 

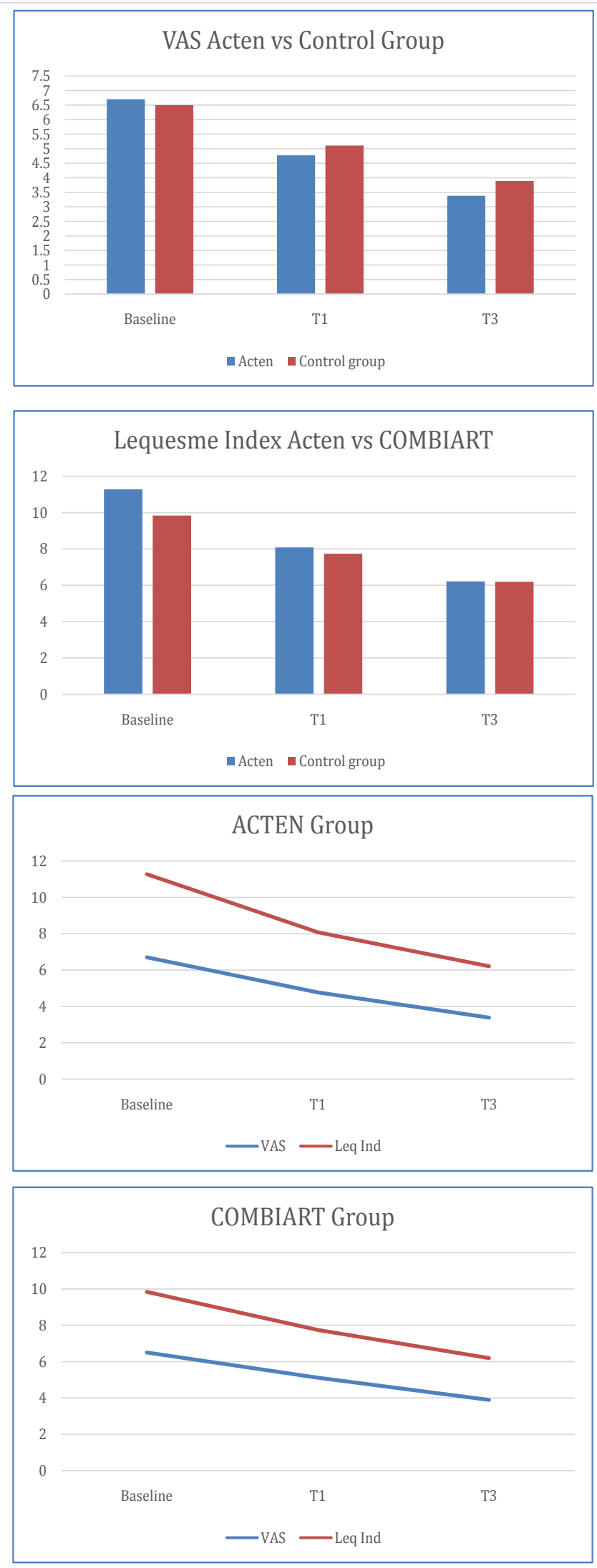

Figure 1:
[20], but many other compounds synthetic or natural have been investigated, including Vitamin C [21-25]. Particular interest has been paid to Collagen Hydrolysates (CHs) and Fucoidans [2644]. $\mathrm{CH}$ is obtained by the enzymatic hydrolysis of collage nous tissues from mammals. The main characteristic of $\mathrm{CH}$ is its amino acid composition, which is identical to type II collagen, thus providing high levels of glycine and proline, essential amino acids for the stability and regeneration of cartilage [28]. This product is recognized as a safe food ingredient by regulatory agencies. $\mathrm{CH}$ is well digested and is preferentially accumulated in cartilage [29]. Clinical use of $\mathrm{CH}$ has not been associated with adverse effects, aside some gastro-intestinal side effects, such as fullness or unpleasant taste.

Fucoidans, on the other side, are a class of sulfated, fucoserich polymers found in several types of brown macroalgae [41, 42] used in a variety of different medical conditions [38]. Several recent studies indicate a role of fucoidan in addressing the symptoms of osteoarthritis. Animal models of collagen induced arthritis showed that orally administered fucoidans successfully inhibited pain [39]. In a small human clinical study osteoarthritis symptoms were inhibited by 12 weeks oral administration of fucoidan rich seaweed extracts by 52\% [40]. There was no reduction in TNF alpha as inflammation marker, but an accompanying study in healthy volunteers showed a decrease in Interleukin 6, a marker for chronic inflammation [43]. Fucoidan's effect on pain has been linked to its selective blockade on neutrophils accumulation [44].

In order to test the clinical efficacy of the combined use of these compounds, CH (Fortigel ${ }^{\circledR}$ 10gr.) and Fucoidan (100mg) $\left(\right.$ ACTEN $^{\circledR}$ ), we have designed a preliminary multicenter randomized clinical trial. Testing its clinical efficacy against another formulation used in clinical practice, based on well known substances: Glucosamine (500mg), Chondroitin Sulfate (400mg) hyaluronic Acid (50 mg) and Vitamin C (100mg) (COMBIART).

\section{Material and Methods}

This trial was designed as a randomized preliminary study. It was conducted over 12 weeks ( 84 days) by a single research group in nine centers (Lazio and Sardinia regions, in Italy) between Oct 2015and May 2016 and involved 126 participants aged 40-65 years, with mild-to-moderate Osteoarthritis (OA) of the knee (grade 2-3 of Kellgren Lawrence grading scale).

Individuals were excluded from the study if they [1] were aged 39 years or younger at the start of the study; [2] had rheumatoid or other forms of arthritis; [3] had joint pain as a result of nerve or muscle damage, accidents, falls, trauma, etc; [4] had comorbidities often associated with osteoarthritis, such as diabetes, cardiovascular disease, elevated cholesterol requiring medical intervention, renal insufficiencies, asthma, or hypertension requiring medical intervention; [5] had cancer within the prior 5 years; [6] were taking any other herbal product or other supplement for pain or inflammation of joints health, such as glucosamine/chondroitin/methylsulfonylmethane, S-adenosylmethionine, or omega-3; [7] were smokers; [8] were heavy alcohol consumers; [9] were pregnant or nursing women; [10] had shellfish allergies; and [11] had a BMI lower than 18.5 (underweight) or greater than 40.0 (morbidly obese) or a body 
weight exceeding $225 \mathrm{lbs}$ (102 kg). The demographics of the patient populations are listed in Table 1.

\section{Intervention}

Participants underwent a 4-week washout period during which they stopped taking all dietary supplements for bones, joints, and inflammation as well as non-prescription drugs.

Prescription drugs that were not related to joint health were allowed, as was OTC rescue medication that was taken only on an as-needed basis. Participating individuals were also asked not to change any aspects of their lives during the 4-week trial. Lifestyle variables were unaltered, including but not limited to diet, fitness regimens, work and family-related tasks.

Participants who passed the initial screening at the baseline appointment were provided with one of the two randomly assigned nutritional supplements (ACTEN $^{\circledR}$ or COMBIART), paper copies of a Visual Analogue Scale (VAS) questionnaire andthe Lequesnealgo-Functional Index (LAI). Each participant was asked to fill out the baseline VAS and LAI questionnaire and return it to the investigator before beginning to take the supplements. The supplements were consumed daily for both groups for the first month. The remaining eight weeks ACTEN ${ }^{\circledR}$ group used the supplement every other day, while COMBIART continued on a daily basis.

Data were collected again at 1 month and 3 months (12 weeks). This approach was chosen to reflect the higher absorption of gel $\left(\right.$ ACTEN $^{\circledR}$ ) compared to capsules (COMBIART) [49].

\section{Outcome Measures}

A VAS scale of 0 to 10 for pain, and the LAI scale of 0 to 24 for pain and functionality were employed to evaluate the 2 measures before and after 4 and 12 weeks of supplementation.VAS scores were reported by asking the participants to mark responses on a $10-\mathrm{cm}$ line. The line contained both end anchor points and 3 additional descriptors that were evenly spaced along the VAS scale at $2.5-\mathrm{cm}$ intervals to help orient the participant. Definitions for the descriptors for each scale are listed in Table 2.

At baseline evaluation, participants were told to notify the research team immediately if any mild, moderate, or severe adverse events occurred during the period of supplementation. During the 1 month follow-up, and again at 3 months participants were once again asked whether they had experienced any adverse events or required any form of rescue treatment (pain or anti-inflammatory drugs) during the supplementation period. No complaints were reported.

The criteria for mild, moderate, and severe adverse events were as follows: (1) mild: an adverse event that does not interfere with usual day-to-day activities and requires no special intervention or treatment; (2) moderate: an adverse event that can affect usual daily activities and that can be addressed with simple therapeutic treatments; (3) severe: an adverse event that requires therapeutic intervention.

\section{Statistical Analysis}

Data gathered from the VAS and LAI questionnaires underwent statistical analysis using a 2-tailed, paired $t$ test to test baseline versus T1 (1 month) and T2 (3 months) for both treatments. Data were cross-analyzed using a 2-tailed non paired $t$ test to compare efficacies. The analyses were performed with the Graph pad PRISM statistical analysis software, version 5.0(La Jolla, CA, USA). The alpha that was used for statistical significance was .05.

\section{Results}

Of the 126 participants enrolled in the study, none withdrew or were removed due to medical complications or lack of compliance with the study's protocol. In comparison with baseline, the results for all participants at the end of the $4 / 12$ weeks for all measures were statistically significant. The ACTEN ${ }^{\circledR}$ group showed a28.5\% decrease in joint pain at 1 month (T1), from a mean VAS score of 6.68 (1.38SD)at baseline to 4.77 (1.98SD) $(P=.0001 ; 95 \% \mathrm{CI}, 1.57,2.25)$ and $\mathrm{a}-49.4 \%$ at T3, mean VAS $3.38(1.78 S D)(P=.0001 ; 95 \% \mathrm{CI}, 2.95,3.65)$. LAI was also reduced by $-28.9 \%$ at $\mathrm{T} 1$, from a mean baseline of 11.28 (3.69SD) to $8.01(P=.0001 ; 95 \% \mathrm{CI}, 2.72,3.82)$ and by $-44.9 \%$ at $\mathrm{T} 3$ mean LAI 6.21 (3.01SD) ( $P=.0001 ; 95 \% \mathrm{CI}, 4.42,5.71)$.

The COMBIART group showed a $21.3 \%$ decrease in joint pain, from a mean VAS score of 6.5 (1.25SD) at baseline to 5.11 (1.53SD) at T1 $(P=.0001 ; 95 \% \mathrm{CI}, 1.09,1.69)$ and $\mathrm{a}-40.1 \%$ at T3 mean VAS 3.89 (1.81SD) ( $P=.0001 ; 95 \% \mathrm{CI}, 2.97,4.33)$. LAI is again reduced by $-21.3 \%$ at $\mathrm{T} 1$ from a mean baseline of $9.84(3.18$ SD) to 7.74 (3.08 SD) $(P=.0001 ; 95 \% \mathrm{CI}, 1.63,2.57)$ and by $-37 \%$ at T3, mean LAI 6.19 (3.04 SD) $(P=.0001 ; 95 \% \mathrm{CI}, 2.97,4.33)$

The ACTEN ${ }^{\circledR}$ group seems to work more efficiently than the COMBIART group (VAS T3 means $-49.4 \% /-40.1 \%$; LAI T3 means $-44.9 \% /-37 \%$ ), but no statistically relevant significance has been detected comparing the two groups.

\section{Summary of Adverse Effects}

No adverse effects were reported during the study.

\section{Discussion}

Osteoarthritis is the most common form of arthritis in Italy

\section{Table 1:}

\begin{tabular}{|c|c|c|c|}
\hline \multicolumn{4}{|l|}{ Population } \\
\hline Age & Meal & 57.10 & SD 8.04 \\
\hline Men & \multicolumn{3}{|c|}{48} \\
\hline Women & \multicolumn{3}{|c|}{78} \\
\hline VAS $\mathrm{cm}$ & Mean & 6.595 & SD 1.318 \\
\hline LAI (Lequesne index) & Mean & 10.595 & SD 3.519 \\
\hline
\end{tabular}

Table 2: Internal descriptors for the VAS Scale, descriptors for LAI are as previously published. (45).

\begin{tabular}{|c|c|}
\hline VAS Value $\mathbf{( c m )}$ & Pain Level \\
\hline 0 & None \\
\hline 2.5 & Mild \\
\hline 5 & Moderate \\
\hline 7.5 & Severe \\
\hline 10 & Worst possible \\
\hline
\end{tabular}


and in the USA [46]. Glucosamine and chondroitin sulfate and hyaluronic acid are natural substances present in and around cartilage cells and, as such, are the most commonly used natural supplements for $\mathrm{OA}$ and joint pain. Previous studies have found them to be effective and safe for addressing the symptoms of $\mathrm{OA}$ $[47,48]$. In particular The Glucosamine/Chondroitin Arthritis Intervention Trial in 2006, sponsored by the National Institutes of Health (NIH), found that glucosamine combined with chondroitin sulfate provided statistically significant pain relief for a subset of participants in comparison with a placebo [20].

In this study we have evaluated the clinical safety and efficacy of ACTEN ${ }^{\circledR}$ (CH 10gr and Fucose $100 \mathrm{mg}$ ) and compared it with a supplement (COMBIART) based on the well- studied effects: glucosamine, chondroitin sulfate, hyaluronic acid and the added value of Vitamin C [21]. As expected the COMBIART group showed a marked reduction in pain and functionality indexes. The decrease in pain and functionality is established in the first 4 weeks of treatment (-21.3\% for both VAS and LAI) and is further increased in the following weeks, up to a $-40.1 \%$ in VAS and $-37 \%$ in LAI at T3 (12 weeks). ACTEN ${ }^{\circledR}$ showed similar results, with a reduction in VAS and LAI at $\mathrm{T} 1$ of $28.5 \%$ and $28.9 \%$ respectively. Again the highest efficacy is reached with prolonged exposure, reaching a $-49.4 \%$ in VAS and $-44.9 \%$ in LAI at T3. Notably the ACTEN ${ }^{\circledR}$ group in the last 8 weeks only assumed the nutritional supplement once every other day, without any loss of efficacy. No statistically relevant difference has been found between the two groups, but larger numbers or prolonged exposures to the supplements might uncover subtler differences.

It has to be taken in consideration that, a daily regimen of ACTEN $^{\circledR}$, instead of an every other day regimen as used in this trial, it is likely to produce further benefits, and it should be investigated.

\section{Conclusions}

Both nutritional supplements (ACTEN ${ }^{\circledR}$ and COMBIART) are safe, well tolerated, and able to exert an important pain reduction and improved functionality in the OA of the knee. Further studies are required to establish pathways for the shown efficacy in pain reduction and radiological studies to check on the structural changes behind the improved functionality of the articulation.

\section{References}

1. Litwic A, Edwards MH, Dennison EM, Cooper C. Epidemiology and burden of osteoarthritis. Br Med Bull. 2013;105:185-189. doi: 10.1093/bmb/lds038.

2. Reginster JY, Bruyere O, Fraikin G, Henrotin Y. Current concepts in the therapeutic management of osteoarthritis with glucosamine. Bull HospJt Dis. 2005;63(1-2):31-36.

3. Largo R, Alvarez-Soria MA, Diez-Ortego I, Calvo E, Sanchez-Pernaute O, Egido J, et al. Glucosamine inhibits IL-1beta-induced NFkappaB activation in human osteoarthritic chondrocytes. OsteoarthrCartil. 2003;11(4):290-298. doi: 10.1016/S1063-4584(03)00028-1.

4. Alvarez-Soria MA, Largo R, Calvo E, Herrero-Beaumont G. Differential anticatabolic profile of glucosamine sulfate versus other antiosteoarthritic drugs on human osteoarthritic chondrocytes and synovial fibroblasts in culture. OsteoarthrCartil. 2005;13(1):S153.

5. Uitterlinden EJ, Jahr H, Koevoet JL, Jenniskens YM, Bierma-
Zeinstra SM, Degroot J, et al. Glucosamine decreases expression of anabolic and catabolic genes in human osteoarthritic cartilage explants. OsteoarthrCartil. 2006;14(3):250-257. DOI:10.1016/j. joca.2005.10.001.

6. Taniguchi S, Ryu J, Seki M, Sumino T, Tokuhashi Y, Esumi M. Long-term oral administration of glucosamine or chondroitin sulfate reduces destruction of cartilage and up-regulation of MMP-3 mRNA in a model of spontaneous osteoarthritis in Hartley guinea pigs. J Orthop Res. 2011;30(5):673-678. doi: 10.1002/jor.22003.

7. Imagawa K, Andres MC, Hashimoto K, Pitt D, Itoi E, Goldring MB, et al. The epigenetic effect of glucosamine and a nuclear factor-kappa $B$ (NF-kB) inhibitor on primary human chondrocytes-implications for osteoarthritis. BiochemBiophys Res Commun. 2011;405(3):362-367. doi: 10.1016/j.bbrc.2011.01.007.

8. Altman RD, Abramson S, Bruyere 0, Clegg D, Herrero-Beaumont G, Maheu E, et al. Commentary: osteoarthritis of the knee and glucosamine. OsteoarthrCartil. 2006;14(10):963-966. doi: 10.1016/j. joca.2006.06.010.

9. Reginster JY, Bruyere 0, Neuprez A. Current role of glucosamine in the treatment of osteoarthritis. Rheumatology (Oxford) 2007;46(5):731735. doi: 10.1093/rheumatology/kem026.

10. Reichelt A, Forster KK, Fischer M, Rovati LC, Setnikar I. Efficacy and safety of intramuscular glucosamine sulfate in osteoarthritis of the knee. A randomised, placebo-controlled, double-blind study. Arzneimittelforschung. 1994;44(1):75-80.

11. Setnikar I, Palumbo R, Canali S, Zanolo G. Pharmacokinetics of glucosamine in man. Arzneimittelforschung. 1993;43(10):1109-1113.

12. Leffler CT, Philippi AF, Leffler SG, Mosure JC, Kim PD. Glucosamine, chondroitin, and manganese ascorbate for degenerative joint disease of the knee or low back: a randomized, double-blind, placebocontrolled pilot study. Mil Med. 1999;164(2):85-91.

13. Rovati L. Clinical development of glucosamine sulfate as selective drug in osteoarthritis. Rheumatol Eur. 1997;26:70.

14. Houpt JB, McMillan R, Wein C, Paget-Dellio SD. Effect of glucosamine hydrochloride in the treatment of pain of osteoarthritis of the knee. J Rheumatol. 1999;26(11):2423-2430.

15. Rovati L. Clinical efficacy of glucosamine sulfate in osteoarthritis of the spine. Rev EspReumatol. 1993;20(S1):325.

16. Muller-Fassbender H, Bach GL, Haase W, Rovati LC, Setnikar I. Glucosamine sulfate compared to ibuprofen in osteoarthritis of the knee. OsteoarthrCartil. 1994;2(1):61-69.

17. Qiu GX, Gao SN, Giacovelli G, Rovati L, Setnikar I. Efficacy and safety of glucosamine sulfate versus ibuprofen in patients with knee osteoarthritis. Arzneimittelforschung. 1998;48(5):469-474.

18. Rovati L. The clinical profile of glucosamine sulfate as a selective symptom modifying drug in osteoarhtritis: current data and perspective. OsteoarthrCartil. 1997;5(SA):72.

19. Reginster JY, Neuprez A, Lecart MP, Sarlet N, Bruyere O. Role of glucosamine in the treatment for osteoarthritis. Rheumatol Int. 2012 Oct;32(10):2959-2967. doi: 10.1007/s00296-012-2416-2.

20.Clegg DO, Reda DJ, Harris CL, Klein MA, O’Dell JR, Hooper MM, et al. Glucosamine, chondroitin sulfate, and the two in combination for painful knee osteoarthritis. N Engl J Med. 2006;354(8):795-808. DOI:10.1056/NEJMoa052771.

21.Peregoy J, Wilder FV. The effects of vitamin C supplementation on incident and progressive knee osteoarthritis: a longitudinal 
study. Public Health Nutr. 2011;14(4):709-715. doi: 10.1017/ S1368980010001783.

22. Malek Mahdavi A, Mahdavi R, Kolahi S, Zemestani M, Vatankhah AM. L-Carnitine supplementation improved clinical status without changing oxidative stress and lipid profile in women with knee osteoarthritis. Nutr Res. 2015 Aug;35(8):707-15. doi: 10.1016/j. nutres.2015.06.003.

23. Oben J, Enonchong E, Kothari S, Chambliss W, Garrison R, Dolnick D Phellodendron and Citrus extracts benefit joint health in osteoarthritis patients: a pilot, double-blind, placebo-controlled study. Nutr J. 2009 Aug 14;8:38. doi: 10.1186/1475-2891-8-38.

24. Witt CM, Michalsen A, Roll S, Morandi A, Gupta S, Rosenberg M, et al. Comparative effectiveness of a complex Ayurvedic treatment and conventional standard care in osteoarthritis of the knee. Study protocol for a randomized controlled trial.Trials. 2013 May 23;14:149. doi: 10.1186/1745-6215-14-149.

25. Ezaki J, Hashimoto M, Hosokawa Y, Ishimi Y. Assessment of safety and efficacy of methylsulfonylmethane on bone and knee joints in osteoarthritis animal model. J Bone Miner Metab. 2013 Jan;31(1):1625. doi: 10.1007/s00774-012-0378-9.

26. McAlidon TE, Nuite M, Krishnan N, Ruthazer R, Price LL, Burstein D,et al. Change in knee osteoarthritis cartilage detected by delayed gadolinium enhanced magnetic resonance imaging following treatment with collagen hydrolysate: a pilot randomized controlled trial. Osteoarthritis and Cartilage. 2011;19(4):399-405. doi: 10.1016/j. joca.2011.01.001.

27. Bannuru RR, Osani M, Vaysbrot EE, McAlindon TE. Comparative safety profile of hyaluronic acid products for knee osteoarthritis: a systematic review and network meta-analysis. Osteoarthritis Cartilage. 2016;24(1):2022-2041. doi: 10.1016/j.joca.2016.07.010.

28. Walrand S, Chiotell E, Noirt F, Mwewa S, Lasse, T. Consumption of functional fermented milk containing collagen hydrolysate improves the concentration of collagen-specific amino acids in plasma. J Agric Food Chem. 2008;56(17): 7790-7795. doi: 10.1021/jf800691f.

29. Bello AE, Oesser S. Collagen hydrolysate for the treatment of osteoarthritis and other joint disorders: a review of the literature. Curr Med Res Opin. 2006;22(11): 2221-2232. DOI:10.1185/030079906X148373.

30. Oesser S, Seifert J. Stimulation of type II collagen biosynthesis and secretion in bovine chondrocytes cultured with degraded collagen. Cell Tissue Res. 2003;311(3):393-399.

31. Schunck M, Schulze CH, Oesser S. Disparate efficacy of collagen hydrolysate and glucosamine on the extracellular matrix metabolism of articular chondrocytes. OA and Cartilage. 2006;14:S114 (Abstract). DOI: $10.1016 / S 1063-4584(07) 60651-7$.

32. Oesser S, Proksc, E, Schunck M. prophylactic treatment with a special collagen hydrosylate decreases cartilage tissue degeneration in the knee joints. OA and Cartilage. 2008;16:S45 (Abstract). DOI: 10.1016/ S1063-4584(08)60119-3.

33. Nakatani S, Mano H, Sampei C, Shimizu J, Wada M. Chondroprotective effect of the bioactive peptide prolyl-hydroxyproline in mouse articular cartilage in vitro and in vivo. Osteoarthritis Cartilage. 2009;17(12):1620-1627. doi: 10.1016/j.joca.2009.07.001.

34. Clark KL, Sebastianelli W, Flechsenhar KR, Aukermann DF, Meza F, Millard RL, et al. 24-week study on the use of collagen hydrolysate as a dietary supplement in athletes with activity-related joint pain. Curr Med Res Opin. 2008; 24: 1485-1496. doi: 10.1185/030079908X291967.

35.Zuckley L, Angelopoulou K, Carpenter MSS, Meredith BA, Kline G, Rowinski $\mathrm{M}$ et al. Collagen hydrosylate improves joint function in adults with mild symptoms of osteoarthritis of the knee. Medecine\& Science in Sports \&Excercise. 2004;36(5):S153-S154. DOI: 10.1249/00005768-200405001-00730.

36. Moskowitz RW. Role of collagen hydrolysate in bone and joint disease. Semin Arthritis Rheum. 2000;30(2):87-99. DOI:10.1053/ sarh.2000.9622.

37. Benito-Ruiz P, Camacho-Zambrano MM, Carrillo-Arcentales JN, Mestanza-Peralta MA, Vallejo-Flores CA, Vargas-Lopez SV, et al. A randomized controlled trial on the efficacy and safety of a food ingredient, collagen hydrolysate, for improving joint comfort. Int J Food SciNutr. 2009;60:99-113. doi: 10.1080/09637480802498820.

38. Fitton JH. Therapies from fucoidan; multifunctional marine polymers. Mar Drugs. 2011;9(10):1731-60. doi: 10.3390/md9101731.

39. Park SB, Chun KR, Kim JK, Suk K, Jung YM, Lee WH. The differential effect of high and low molecular weight fucoidans on the severity of collagen-induced arthritis in mice. Phytother Res. 2010;24(9):13841391. doi: $10.1002 /$ ptr.3140.

40. Myers SP, O'Connor J, Fitton JH, Brooks L, Rolfe M, Connellan P, et al. A combined phase I and II open label study on the effects of seaweed extract nutrient complex on osteoarthritis. Biologics. 2010;4:33-44.

41. Kiple KF, Ornelas KC. Important Vegetable Supplements. In: Beck SV, editor. The Cambridge World History of Food. Vol. 1. Cambridge University Press; Cambridge, UK: 2000. pp. 231-249.

42. Berteau 0, Mulloy B. Sulfated fucans, fresh perspectives: Structures, functions, and biological properties of sulfated fucans and an overview of enzymes active toward this class of polysaccharide. Glycobiolog. 2003;13(6):29-40. DOI:10.1093/glycob/cwg058.

43. Myers SP, O’Connor J, Fitton JH, Brooks L, Rolfe M, Connellan P, et al. A combined Phase I and II open-label study on the immunomodulatory effects of seaweed extract nutrient complex. Biologics. 2011;5:45-60. doi: 10.2147/BTT.S12535

44. Cunha TM, Verri WA, Jr Schivo IR, Napimoga MH, Parada CA, Poole $\mathrm{S}$, et al. Crucial role of neutrophils in the development of mechanical inflammatory hypernociception. J Leukoc Biol. 2008;83(4):824-832. doi: $10.1189 /$ jlb.0907654.

45. Lequesne MG. The algofunctional indices for hip and knee osteoarthritis. J Rheumatol. 1997;24:779-781.

46. Felson DT, Zhang Y. An update on the epidemiology of knee and hip osteoarthritis with a view to prevention. Arthritis Rheum. 1998;41(8):1343-1355. DOI:10.1002/1529. 0131(199808)41:8<1343::AID-ART3>3.0.C0;2-9.

47. Matheson AJ, Perry CM. Glucosamine: a review of its use in the management of osteoarthritis. Drugs Aging. 2003;20(14):1041-1060.

48. Uebelhart D, Thonar EJ, Delmas PD, Chantraine A, Vignon E. Effects of oral chondroitin sulfate on the progression of knee osteoarthritis: a pilot study. Osteoarthritis Cartilage. 1998;6 (suppl A):39-46.

49. Raats SK, Shamliyan TA, Redmon JB, Vimmergrem NJ, Donadio JV, Bibus DM. Bioavailability and Nutrients: Capsules vs Gel delivery. Journal of American Dietetic Association 2009 109; 6:1076-1081. 